\title{
The Redistributive Effect of China's Personal Income Tax
}

\author{
Jingxin $\mathrm{Hu}^{1}$ Xilan Chen ${ }^{1}$ \\ ${ }^{1}$ Department of Public Economics, Xiamen University, Xiamen, China
}

\begin{abstract}
In 2011, a five-year plan was published, which proposed an aim to reverse the trend of a widening income gap as soon as possible, and put an emphasis on playing the role of personal income tax in perfecting redistribution adjustment mechanism. So a reasonable and well designed personal income tax system is vital to fulfill such aim. In this paper, we perform mathematical analysis of redistributive effects. We also perform empirical analysis of personal income tax systems in China, to diagnose causes of ineffective income redistribution resulted from personal income tax regulation in China.
\end{abstract}

Keywords: income distribution effects, personal income tax, empirical analysis

\section{Instruction}

In recent years, the problems of uneven distribution as well as widening income gap between rich and poor are highly regarded by the Chinese Government. In fact, the government was greatly determined to reverse the trend of a widening income since several years ago and repeatedly opted for reforms of personal income tax: raising the threshold, adjusting the tax rate from "nine grades excess progressive rates" to "seven grades excess progressive rates". However, the function of personal income tax in regulating income distribution is still argued by different parts of the society.

As we know, three main factors determine the redistributive effects of personal income tax: the design of tax rate and tax grade, exemption and expense deduction. In these years, the reform in personal income tax system mainly focused on adjusting exemption while relatively less attention was paid to the design of tax rate and tax grade. Thus, in this paper, we first build mathematical models to compare the merits or defects of different exemptions and different designs of tax rate and tax grade, and then we perform empirical analysis based on practical data in China to probe into the basic issues in redistributive effect of personal income tax system.

\section{Theoretical analysis}

In this paper, we roughly divide primary income distribution into five levels according to Zuguang Hu's quinquepartite method of income in computing Gini coefficient:

$$
G=\frac{\left(y_{5}-y_{1}\right)}{\left(y_{1}+y_{2}+y_{3}+y_{4}+y_{5}\right)} \cdots(1)
$$

We consider Simple Tariff System and Progressive Tax in Excess of Specific Amount System in this paper and we will calculate the post-tax Gini coefficient and analyze the redistributive effect of personal income tax.

\subsection{Simple Tariff System}

[1] Exemption $y_{0} \leq y_{1}$ : 
Post-tax Gini coefficient is

$$
G_{T 1}=\frac{\left(\bar{y}_{5}-\bar{y}_{1}\right)}{\left(\bar{y}_{1}+\bar{y}_{2}+\bar{y}_{3}+\bar{y}_{4}+\bar{y}_{5}\right)} \cdots
$$

We use $\mathrm{G} / \mathrm{G}_{\mathrm{T} 1}$ to represent pre-tax Gini coefficient to post-tax Gini coefficient ratio. A ratio that is greater than 1 indicates positive redistributive effect of personal income tax. That is to say, the more significant the redistributive effect of personal income tax is, the greater the ratio will be.

$$
\frac{G}{G_{T 1}}=1+\frac{5 \tau y_{0}}{(1-\tau)\left(y_{1}+y_{2}+y_{3}+y_{4}+y_{5}\right)} \cdots
$$

From the expression of the ratio G/GT1, we know it is determined by exemption and tax rate and it is always greater than 1 . The greater the exemption $y_{0}$ is, the higher the tax rate is, the more significant the redistributive effect of personal income tax will be. We do not consider high tax rate because it will have bad impacts on labor supply and other economic factors.

[1] $y_{1}<y_{0}<y_{5}$ :

(1) $y_{1}<y_{0}<y_{2}$ the post-tax Gini coefficient is:

$G_{T 21} \rightarrow \frac{(1-\tau)\left(y_{5}-y_{1}\right)}{(1-\tau)\left(y_{1}+y_{2}+y_{3}+y_{4}+y_{5}\right)+5 \tau y_{0}}\left(y_{0} \rightarrow y_{1}\right) \cdots(4)$

With the increase of $y_{0}$, we have $\mathrm{G}_{\mathrm{T} 21} \leq \mathrm{G}_{\mathrm{T} 1}$ and $\mathrm{G} / \mathrm{G}_{\mathrm{T} 21} \geq \mathrm{G} / \mathrm{G}_{\mathrm{T} 1} \geq 1$. So, when using the Simple Tariff System, the increase of exemption will contribute to the redistributive effect of personal income tax.

(2). $y_{2}<y_{0}<y_{3}$ we can obtain:

$$
\begin{aligned}
& G_{T 22}=\frac{(1-\tau) y_{5}+\tau y_{0}-y_{1}}{(1-\tau)\left(y_{1}+y_{2}+y_{3}+y_{4}+y_{5}\right)+\tau\left(y_{1}+y_{2}\right)+3 \tau y_{0}} \\
& <\frac{(1-\tau)\left(y_{5}-y_{1}\right)+\tau\left(y_{0}-y_{1}\right)}{(1-\tau)\left(y_{1}+y_{2}+y_{3}+y_{4}+y_{5}\right)+\tau y_{1}+4 \tau y_{0}}=G_{T 21} \cdots(5)
\end{aligned}
$$

Similarly, we can get $\mathrm{G}_{\mathrm{T} 23}>\mathrm{G}_{\mathrm{T} 22}$ when $\mathrm{y}_{3}<\mathrm{y}_{0}<\mathrm{y}_{4} ; \mathrm{G}_{\mathrm{T} 24}>\mathrm{G}_{\mathrm{T} 23}$ when $\mathrm{y}_{4}<\mathrm{y}_{0}<\mathrm{y}_{5}$.
From the mathematical analysis of redistributive effect of Simple Tariff System above, we know that the increase of exemption will contribute to the redistributive effect of personal income tax. However we must pay attention to the distortion effects of tax that might affect labor supply, which cannot be represented by mathematical models. As a result, the increase of exemption should be moderate with the Simple Tariff System.

\subsection{Progressive Tax in Excess of Specific Amount System}

[1] Exemption $y_{0} \leq y_{1}$.

$$
G_{T 31}=\frac{\left(y_{5}-y_{1}\right)+\left[t\left(\hat{y}_{1}\right)\left(y_{1}-y_{0}\right)-t\left(\hat{y}_{5}\right)\left(y_{5}-y_{0}\right)\right]}{\left(y_{1}+y_{2}+y_{3}+y_{4}+y_{5}\right)+\sum_{i=1}^{5}\left[t\left(\hat{y}_{i}\right)\left(y_{0}-y_{i}\right)\right]} \cdots(6)
$$

When $y_{0} \rightarrow y_{1}$, we can obtain:

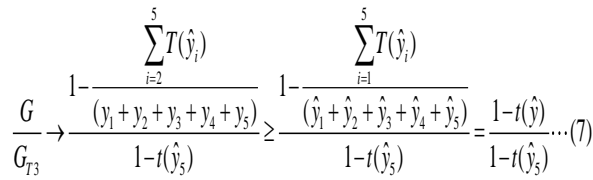

Where $t(\hat{y})$ is the average tax rate.

With the Progressive Tax in Excess of Specific Amount System, the average tax rate $t(\hat{y})$ is less than the average tax rate of the richest $\mathrm{t}\left(\hat{\mathrm{y}}_{5}\right)$, so we can get $\mathrm{G} / \mathrm{G}_{\mathrm{T} 3}>1$ and reach to a conclusion that personal income tax has redistributive effects. In addition, the wider the income gap is, the greater the $\mathrm{G} / \mathrm{G}_{\mathrm{T} 3}$ will be, which indicates the more significance of redistributive effect.

\section{Empirical analysis}

It has became a standard method (Adam Wagstaffa , Eddy van Doorslaerb, etc,1999) to evaluate the redistributive effects of income tax by using the difference between pre-tax Gini coefficient and post-tax Gini coefficient. Gini coefficient was developed by Italian 
statistician Corrado Gini in 1912, a ratio lies between 0 and 1, to comprehensively analyze and quantitatively measure the difference of residents' income distribution within a certain country.

In practice, researchers often use another simple formula to calculate Gini coefficient（Jianlin Dai, 2000） :

$$
G=\sum_{i=1}^{n} W_{i} Y_{i}+2 \sum_{i=1}^{n-1} W_{i}\left(1-V_{i}\right)-1 \cdots(8)
$$

Where $\mathrm{W}_{\mathrm{i}}$ denotes the percentages of people grouped by income. $\mathrm{Y}_{\mathrm{i}}$ denotes the share of gross income of each group in total income. Vi denotes the sum of $\mathrm{Y}_{\mathrm{i}}$, i.e. $V_{i}=Y_{1}+Y_{2}+Y_{3} \cdots+Y_{i}$.

\subsection{Empirical analysis of redistributive effects of personal income tax}

In this paper, we choose the data of "basics of urban households" published in China Statistical Yearbook from 2003 to 2010 to estimate Gini coefficients. The sample data is grouped by income, in ascending order, into 7 groups, with the percentages of $10 \%, 10 \%, 20 \%$ 、 $20 \% 、 20 \% 、 10 \% 、 10 \%$. The number of households, the proportion of respondents, average population of each family, annual income per head and disposable income per head are listed in each group. We use data of annual income per head to calculate pre-tax Gini coefficients.

In this paper, we choose the data of "basics of urban households" published in China Statistical Yearbook from 2003 to 2010 to estimate Gini coefficients. We employ equation

$$
G=\sum_{i=1}^{n} W_{i} Y_{i}+2 \sum_{i=1}^{n-1} W_{i}\left(1-V_{i}\right)-1 \cdots(9)
$$

together with survey data of "basics of urban households" to calculate pre-tax Gini coefficients and post-tax Gini coefficients from 2003 to 2010. And we use these Gini coefficients to calculate the redistributive effects of personal income tax which are listed in table 3.1.

Table 3.1 redistributive effects of personal income tax from 2003 to 2010

\begin{tabular}{|c|c|c|c|c|}
\hline Year & $\begin{array}{c}\text { pre-tax Gini } \\
\text { coefficients }\end{array}$ & $\begin{array}{c}\text { post-tax Gini } \\
\text { coefficients }\end{array}$ & $\begin{array}{c}\text { redistributive } \\
\text { effects }\end{array}$ & $\begin{array}{c}\text { Drop of Gini } \\
\text { coefficients(\%) }\end{array}$ \\
\hline 2003 & 0.33365467 & 0.33330208 & 0.00035259 & 0.1057 \\
\hline 2004 & 0.32932102 & 0.32927927 & 0.00004175 & 0.0127 \\
\hline 2005 & 0.32458148 & 0.32516096 & -0.00057948 & -0.179 \\
\hline 2006 & 0.32147662 & 0.32075276 & 0.00072385 & 0.2252 \\
\hline 2007 & 0.32241150 & 0.32161732 & 0.00079418 & 0.2463 \\
\hline 2008 & 0.32055108 & 0.31978114 & 0.00076994 & 0.2402 \\
\hline 2009 & 0.31167811 & 0.31082984 & 0.00084827 & 0.2722 \\
\hline 2010 & 0.30579956 & 0.30511767 & 0.00068189 & 0.223 \\
\hline
\end{tabular}

(In this table, the tax means personal income tax, does not include other taxes.)

Table 3.1, graph 3.1 and graph 3.2 indicate the tiny redistributive effects of personal income tax with little variation in absolute or relative value of Gini coefficient, a few parts in ten thousand in absolute value and less than $1 \%$ in relative value.

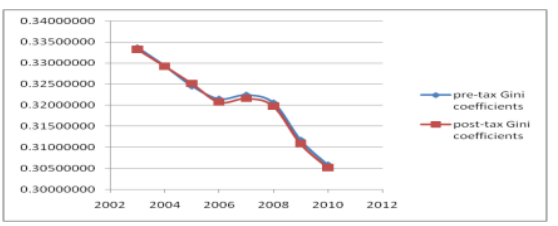

Graph 3.1 Pre-tax Gini coefficient and posttax Gini coefficient (personal income tax)

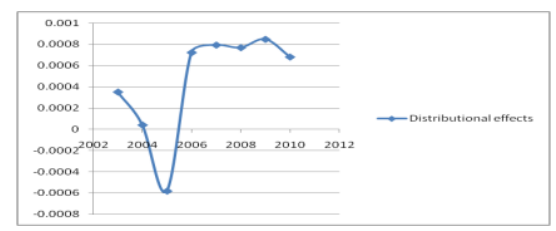

Graph 3.2 redistributive effects of personal income tax

According to the curve trend in graph 3.2, we know each time China made timely and effective decisions to adjust exemptions, which bettered the redistribution function of personal income tax. However, the basic part of the redistribution function of personal income tax was not changed. For instance, the post-tax Gini coefficient was greater than pre-tax Gini coefficient by $0.179 \%$ 
in 2005 and the redistributive effects was a negative. In 2006, after the adjustment of exemption from 800 to 1600 , the posttax Gini coefficient became less than pretax Gini coefficient by $0.2252 \%$ and the redistributive effects became a positive.

\subsection{Analysis of empirical results}

In the discussion above, we find reasonable Gini coefficient of residents and negligible redistributive effects of personal income tax. We will try further discussion about the causes:

Tax system: The tax system in China is executed with turnover tax system mainly and the personal income tax makes up small share of total tax revenue. In 2010, personal income tax accounted for $6.6 \%$ in total tax revenue. As a result, small share of personal income tax leads to limited income redistribution function.

Income sources: The existing of large amount of abnormal income, illegal income and gray income contributes to uneven income distribution in China. For a long time, these types of income are excluded from the taxing of personal income tax. In such case, the income redistribution function is certain to be limited. In this paper, we calculate the Gini coefficient based on normal income which may leave out much information and lead to results inconsistent with social reality.

\section{Acknowledgements}

This work was financially supported by the Fujian province soft project (2012R0079).

\section{Conclusion}

In fact, the key of wide income gap lies in the huge disparity of wealth distribution, and personal income tax cannot adjust the stock of income distribution. To solve the problem of huge income gap, new policies are needed to accelerate the establishment of tax system, such as property taxes and inheritance taxes. The adjustment of personal income tax is limited in the part of income flow, which cannot fundamentally change the trend of widening income gap. So, government should put emphasis on primary distribution, enhance tax supervision, especially the tax supervision of abnormal income, to improve the situation of income distribution in China.

\section{References}

[1] Adam Wagstaffa, Eddy Van Doorslaerb etal. Redistributive Effect, Progressivity and Differential Tax Treatment: Personal Income Taxes in Twelve OECD Countries [J]. Journal of Public Economics, 1999, (72): 73 98.

[2] Eduardo M.R.A Engel, Alexander Galetovic and Claudio E. Raddatz. Taxes and Income Distribution in Chile: Some Unpleasant Redistributive Arithmetic [J]. Journal of Development Economics, 1999, (59): 155-192.

[3] Lambert, P. J. On the Redistributive Effect of Taxes and Benefits [J]. Scottish Journal of Political Economy, 1985, (32): 39-54.

[4] Richard M. Bird and Eric M. Zolt. Redistribution via Taxation: the Limited Role of the Personal Income Tax in Developing Countries [J]. 52 UCLA Law Review, 2004-2005: 1627-1695.

[5] Jianlin Dai. How to calculate the Gini coefficient $[\mathrm{J}]$. Zhejiang statistics, 2000, (4): 37

[6] Zuguang Hu. A Study of the Best Theoretical Value of Gini Coefficient and Its Concise Calculation Formula [J]. Economic Research, 2004, (9), 60-69 